\title{
Traditional Najdi Settlement Architectural Elements: Harmonizing Function, Aesthetics, and Shared Socio-Cultural Meaning
}

\author{
Mohammed Mashary Alnaim \\ Department of Architectural Engineering, College of Engineering, University of Hail, Hail, Saudi Arabia \\ moha.alnaim@gmail.com
}

(Received 5/7/2020; accepted for publication 27/8/2020.)

\begin{abstract}
The built form contains symbols ("architectural elements") that express embedded meanings about the place and about those to whom the symbols belong. The architectural elements presented in this paper provide evidence for how deeply felt socio-cultural principles were transmitted to tangible physical objects and how those physical objects then embedded socio-cultural meanings to inhabitants. Examining the architectural element from the perspective process of making them helped to identify several concepts and principles that directly influenced the traditional Najdi built environment. The aim is to understand how the aesthetic appearance of the elements characterized the identity of traditional Najd settlements and how these elements contained multiple functions and varied meanings as understood, and as agreed to, by the local inhabitants.
\end{abstract}

Keywords: Element; symbol; culture; Najd; urban form; process; principle; 'tarma'; 'furaj'; 'shuraf'.

\section{Introduction}

Although the traditional Najdi built environment is introverted rather than extroverted, certain architectural elements were developed over the course of centuries to support urban life in the traditional settlements. Although the traditional Nadji settlements are now mostly uninhabited, this relationship between architectural elements and urban life may be understood by examining the built environment that remains today. We have recently performed an in-depth study of five Nadji settlements: Ad-Diriya, Sudus, Alkhabra, Ushaiqer, and old Riyadh, in a region in Saudi Arabia. The external form of the traditional settlement built environments mostly adopted a solid mass with a compacted urban form. The few openings that do exist to the outside include the requisite entrances as well as small windows at the top of the second floor. From the study's general observations, most, if not all, architectural elements emerged in a way that served to support the built environment's spatial order while also serving to enhance the notion of a harmonious built environment. Thus, the architectural elements emerged in response to specific local needs and provided visual components that characterize the built environment and influence its identity.

The study observed that the traditional settlements exhibit a hierarchal order of spaces, relocating various elements according to their function, thereby providing a balance between private and public space: the private indoor space of buildings and the public outdoor space of urban spaces (Alnaim, 2020). This can explain why some elements were only observed and identified in specific spaces and areas within the built form as the process of change respected the spatial order and maintained its existence through the support of the collective actions that people took in the built environment over centuries. The existence of the hierarchical order allowed for flexibility in 
people's daily actions and decisions, and this is part of the inner dynamic features of the spatial order. Rapoport reached a similar conclusion, and he built on this idea to explain how establishing collective decision-making at the macro and micro-level impacts the quality of the built environment and forms its identity. He argues that this type of process helped related communities establish an ideal setting for their unified group, a setting representing their shared socio-cultural values through physical forms and shared meanings (Rapoport, 1969).

Before examining the architectural elements, it is essential to elaborate upon and explain what is meant by how culture influences a physical form's process of making, to grasp briefly how social principles and physical objects interact and can be transmitted through forms and meanings. In that sense, Geertz stressed that understanding the cultural role is essential and he argued that culture is not a given, and people are not born with it. He points out that culture is metaphorically the core of what makes us human and sets us apart, rather than something else. Geertz notes that "Culture is best seen not as complexes of concrete behavior patterns, but as a set of control mechanisms" (Geertz: 1973). Damen supports this, asserting that "Culture is mankind's primary adaptive mechanism" (Damen, 1987). Edward Hall as well stated that "Culture is communication, and communication is culture" (Cited in Damen, 1987). From this perspective it is possible to view culture as Amos Rapoport described: having a high power to control the distribution of buildings and the possession of culture is what is taken to define humans (Rapoport, 1969, 1977, 1987, 2005). This means that in order to understand how the local people of Najd, Saudi Arabia, arranged and distributed their traditional urban and building structures one should, first, understand the cultural settings of the local communities ${ }^{1}$.

The importance of use and meaning as a process may help to understand how to interpret a precultural environment from a cultural perspective and how use and meaning were manifested through spatial and physical forms.

(1)The concept of how culture has a strong influential factor in the process of generating the built environment has been extensively presented by numerous scholars (Rapoport, 1969, 2005; Duncan, 1981; Habraken, 1985; Benswessi, 1987; Mol, 1978; Bloom, 1990; Hakim, 1990; and many others).
In general, meanings are associated with symbols which implies that symbol embodies strong meanings that have a collective social and cultural agreement. In most traditional built environments, people invent and use spatial and physical symbols as non-verbal communication tools (Hakim, 1997).

In this situation, James Duncan gives us a clear perspective of how socio-cultural forces worked in combination to influence the creation of traditional built environments. He examined the relationship between collectivistic and individualistic social structures and the attitudes of people toward the meaning of the house. He characterizes collectivistic social structures as having a relatively closed social group, demonstrating a high level of kinship, and exhibiting a shared, stable value system (Duncan, 1981). The example presented by Duncan in the collectivistic group is groups where gender segregation is primary. The house (physical form) in such a collective group is more oriented toward private spaces, where the house is a "container of women" (Duncan's term) while men in these types of societies are more oriented toward public space.

What is valuable in this anatomic cultural analysis is that it helped in discovering the reasons behind the existence of the spatial and physical forms. The associated meaning attached to the house (physical form), as Duncan describes, is a container to value women. This meaning is associated in this type of group because women spend most of the time in the house for cooking or raising children, which make the women more oriented toward the private social space (Duncan, 1981). Moore also attempts to determine the reasons behind the house's configuration, when he stresses that the home exists as a cultural symbol, primarily through its relationship with gender roles (Moore, 2000). This approach to analysis is crucial for this study because it enabled us to identify heretofore unrecognized relationships in the traditional built environment.

That said, examining architectural elements from the perspective of the Islamic traditions (Urf's) ${ }^{2}$ that characterized the Najdi social structure led to an appreciation for the significant influence of social principles and forces on organizing and establishing a binder between space and place that

(2) Basim Hakim describes Urf as the custom derived from Islamic jurisprudence, the accepted habit, act, and way of doing something within a confined ruling system based on the knowledge and understanding of a locality. He argues that most Islamic cities tend to generate similar characteristics due to the sharing of Urf practice, which is common to most Islamic communities (Hakim, 1986). 


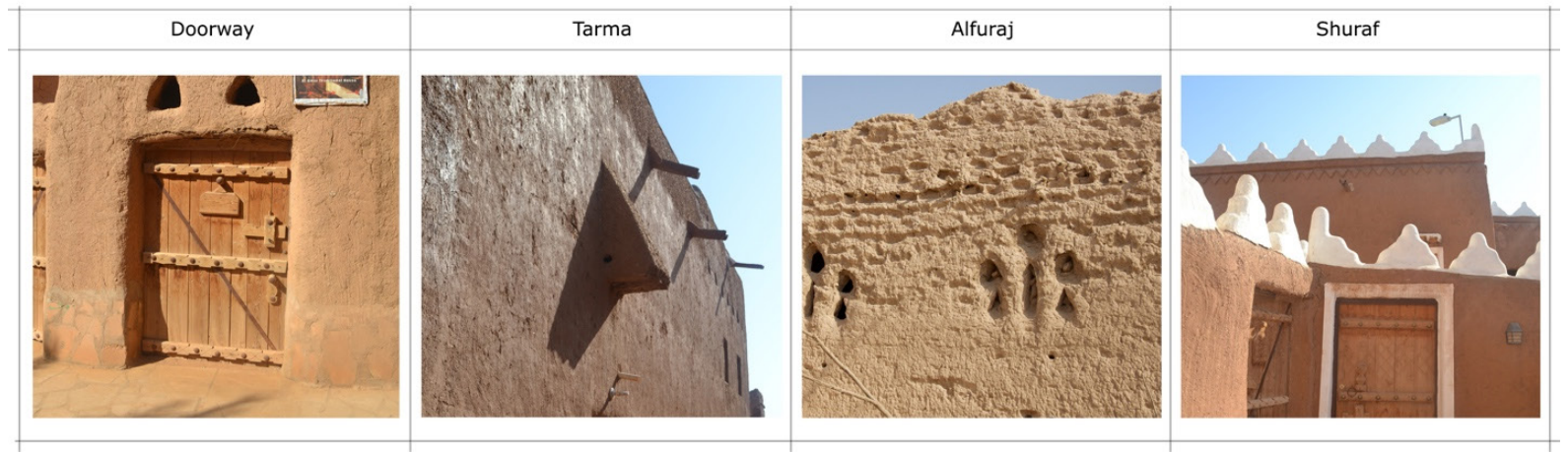

Figure 1. Examples of the four architectural elements. Source: Author

formed the character and embedded meanings of the traditional Najd built environments ${ }^{3}$. In the following sections, the discussion continues by introducing and examining architectural elements.

\section{The Elements}

The analysis in this article focuses on the architectural element as products and as a result of the continuous process of making that generated the urban spaces and building masses which together form the built environment. Five Najdi settlements - Ad-Diriya, Sudus, Alkhabra, Ushaiqer, and old Riyadh - were chosen and the study focused on four architectural elements - Doorway, Tarma, Alfuraj, and Shuraf - found in these traditional Najdi settlements. The study measured these architectural elements to understand how principles such as socio-cultural factors, environmental settings, construction knowhow, religious convictions, etc., influenced them and how the elements served their urban and building functions (Figure 1).

Each of the four element types became justified according to their socio-cultural importance, their response to the demands imposed on inhabitants by the natural environment, and the main function that led to creating them. That said, examining the

(3) The traditional built environment in Najd is a result of external forces such as topography, climate, and technology and, more importantly, internal forces such as socio-cultural drivers such as religion, customs, shared societal agreement and values. Usually, in the traditional Arab towns, the irregular organic urban forms were governed by an internal order which was mainly developed from the interaction between socio-cultural aspects, local know-how, technology, and natural environment. This is different from the preplanned city systems (Al-Hathloul, 2010; Bianca, 2000; Hakim, 1986; Ragette, 2012). elements from the perspective of the traditions (Urf's) that characterized the Najdi social structure led to the appreciation that social principles and forces have a significant influence on organizing and establishing a binder between space and place and formed the character and meanings of the built environment ${ }^{4}$. The objective is to examine how an element's use and meaning can change according to how users perceive the element from the perspective of the urban space or from the perspective of the building.

The architectural elements, we argue, are always governed by the higher processes within the built environment which make them, as a whole, always respond to the main local atmosphere that led to establishing the built environment's characteristics. In this case, the more integrated the architectural element is with the religious convictions and socio-cultural factors of inhabitants, the more the element became constant and unchanging. Meanwhile, elements that merely served some technical or environmental purpose are effectively more flexible: typically, inhabitants modified them over time and the elements became associated with social meanings that later become an integral part within the built form order.

\section{Methodology}

The study made use of collecting data for the four elements in four steps. The first step included

(4) A mix of religious, cultural, and social customary (Urf) values worked together to generate the traditional built environments. They can be seen as a "mechanism of societal behavior" that can produce similar or distinctive characteristics for each city or settlement (Hakim, 1986). 
collecting available documents such as maps and images that illustrate and visually describe the various aspects of each element and its variable location such as site plans of traditional settlements, road patterns, open spaces, public building distribution, private building distribution, etc. The second step was narrative, and it determined how the study organized historical data by classifying the data into two categories: primary data and secondary data. The third step focused on validating the data by conducting focus group interviews supplemented by in-depth, one-on-one interviews, document classification, and a thorough review of the literature concerning the traditional elements of the Najdi built environment. The fourth step comprised conducting site visits to observe the urban and architectural components and how they relate to each other and how they function. We employed the use of graphical resources as well as historic settlement period documents supplemented by the historical archives to observe the spatial and physical components of each settlement deeply. The aim was identifying the elements, their location, and determining their use and meanings.

\section{The Element of Doorway}

The doorway, locally named Al-Bab (pl. Abwab), typically functions as an access element to a house or building. This element can express some of the most important aspects of social and economic life for inhabitants. The Al-Bab is an element that non-verbally acknowledges and describes the social and economic status of a house's owner. Doorways appear in many different styles, shapes, and use of ornamentation, serving to communicate an owner's wealth and lifestyle to the community (Al-Anbar, 1999). The quality, accuracy and craftsmanship of the wood craft, the use of floral motifs of nature, geometrical forms, or religious writings directly reflect the house owner's social status and priorities (Al-Nowasier, 1999). This means that an elaborately decorated door typically indicated a higher level of wealth and a higher standard of living of its owner. On the other hand, a door with simple, inexpensive materials that contained no decoration indicated a lower level of wealth and a lower standard of living of its owner (ADA, 2015). It is worth noting, however, that this is not always the case: some inhabitants with religious convictions may have been wealthy, but they eschewed high levels of ornamentation based on their religious beliefs.

Having examined the different door placements in the traditional settlements, it is clear that the door element embodies dual meaning 5 . The meaning changes depending on how inhabitants use the door and to whom it serves (men/guest door or private family door). The different social meanings that the door embodies are encoded by local craftsmen based on how the element is physically presented within the built environment and understood by the local people (Figure 2).

The doorway and its visual features define the house and its residents. It is possible to say that this element worked as an important visual representation that guided local people to "name" the house and identify its location. This is because in most cases, we found few other external visual elements in the traditional Najdi settlements which led the doorway element to be that much more prominent. In many cases, the inhabitants described the features of a doorway to guide anyone (especially visitors) to the house by describing its visual appearance, use of color, and ornamentation. This behavior is among the many communication tools that local people developed and used for centuries to employ the architectural visual elements to orient themselves and visitors within their built environment.

Where there are two doors providing access to a building, the guest door is usually wide, decorative and colorful, while the family doorway is narrow and has less ornamentation. Occasionally we noticed a setback among doors in narrow pathways (Figure 3). Also, when the building is located near public or semi-public streets, the guest door is usually more prominent while the family door is more hidden. In this situation, the door decoration functions as a communication tool to guide guests to the doorway they should use, while also reflecting the social status of its owner. This mechanism regulates social interaction and it is part of the wider palette of common elements core concepts that may be found in the

(5) The dual meaning described here arises from the doorway being an element that serves both the urban spaces outside the building and the private spaces inside the building. As a result, from the perspective of the urban space, the doorway can embody a particular meaning, while from the perspective of within the building the doorway can have a completely different meaning. 

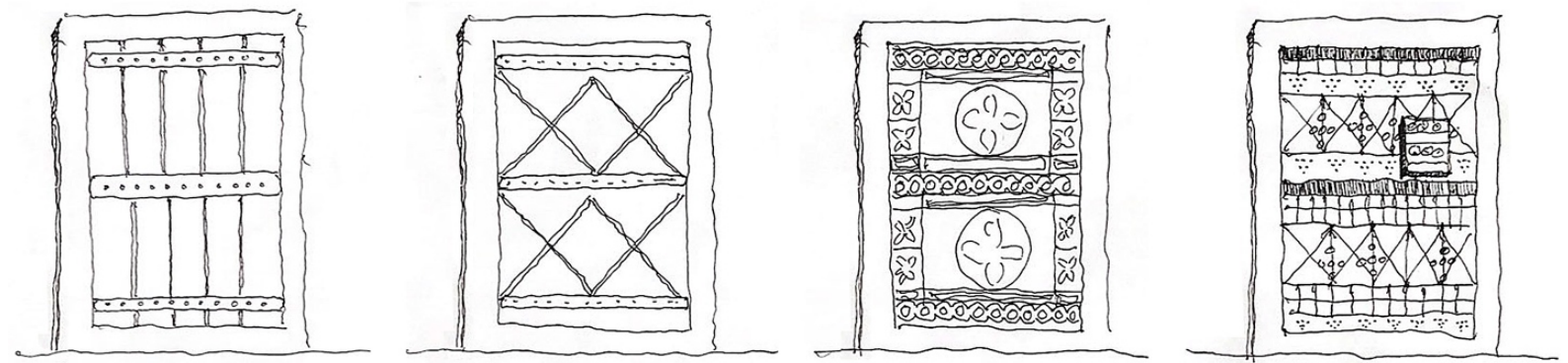

Basic

Ornamentation
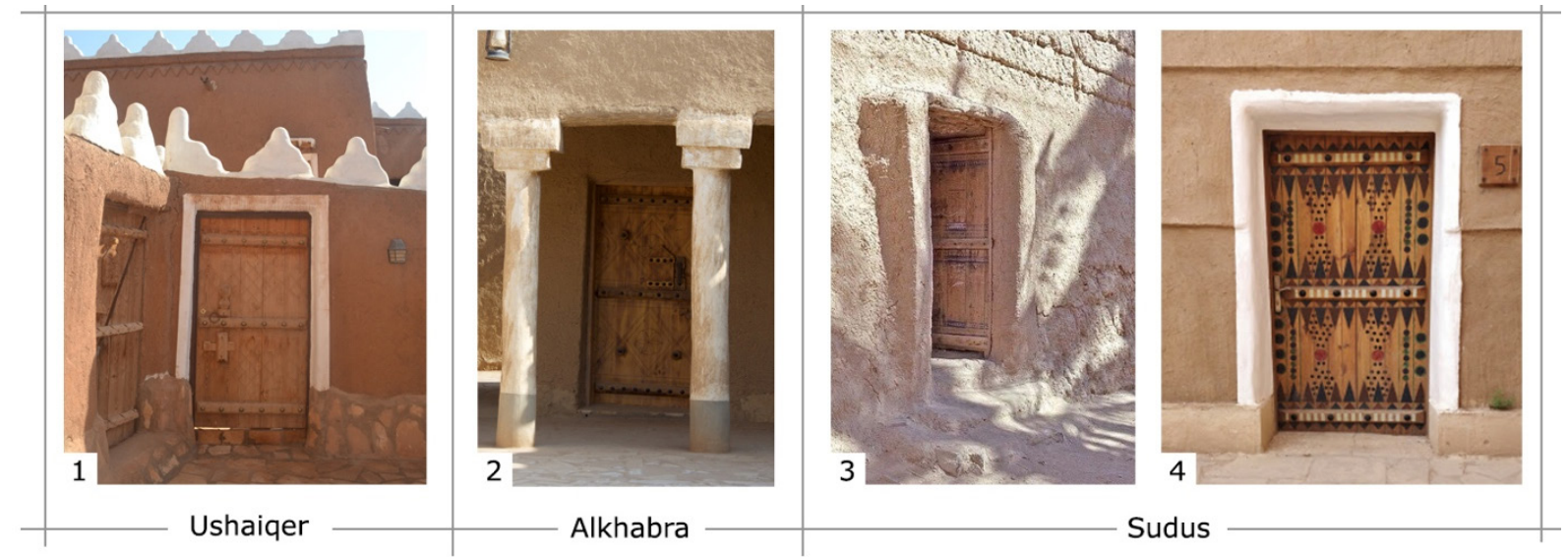

Figure 2. Different physical representations of door ornamentation found in the traditional Najdi built environment. Image Sources: (1, 2) Author, (3) Ibrahim al-Oudaibi, and (4) Inam Alhaq
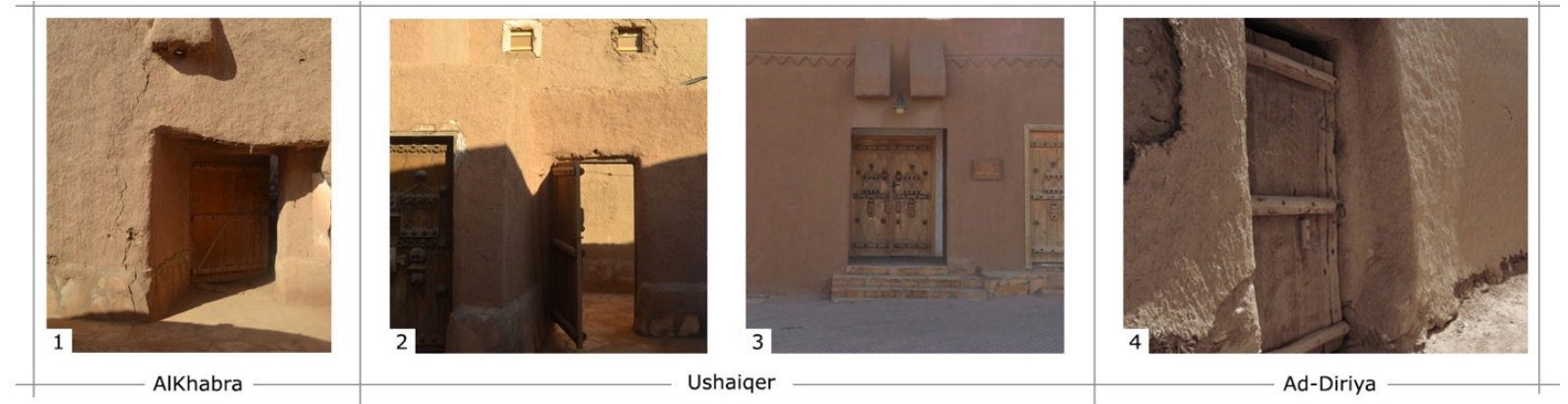

Figure 3. A number of traditional house doorways. $(1,4)$ a family/guest door with a setback and basic ornamentation $(2)$ a family door with narrow width, and (3) a guest door with wide and decorative elements. Source: (1, 2, and 3) Author, (4) ADA

traditional Najdi settlements. Therefore, we argue that the doorway is not only an element that involves accessibility, but it also functions as a dialectical element that serves to achieve a level of non-verbal interaction between dwelling owners and guests as well as the general public.

The door, as described, can represent different meanings based on the level of ornamentation, and the community understood this ornamentation non-verbally. This is why in the case of wealthy people who have two doors, it is found that the family door still has less ornamentation, while the main guest door has more ornamentation as it will most likely be seen by their guest ${ }^{6}$. This

(6) Al-Anbar mentions that if the family door is highly ornamented, this indicated an extreme level of wealth held by the door's owner, which was a rare behavior in the Najdi built environment (Al-Anbar, 1999) (see also Jomah, 2009; Al-Saud, 2017). 
reflects the idea that people always have a tendency to utilize their resources for their necessities and tend to simplify their built environment unless there is a social or natural need to do otherwise.

The importance of this observation is that it can help understand how the traditional local community developed a visual representation mechanism by using a simple architectural element - the door - to express the different levels of their social life. This mechanism did not affect the main principles of the doorway in the spatial order, its placement and to whom it serves (guest or family). This is significant as this means that the different styles, shapes, colors, and use of ornamentation of the door element are all used to support non-verbal communication and to help the locals differentiate between houses and sometimes between door functions in the traditional Najdi built environment?

\section{The Element of Tarma}

Tarma (pl. Tarmat) is a mud or wooden element seen in exterior building walls and near the house door (typically, above the door) for female residents to watch silently who is outside through its small holes seen at the bottom of its base (Al-Nowasier, 1999). The term "Tarma" in Arabic means the person who cannot speak, and the term is associated with the architectural element due to its main function, which is to observe the streets and see who's knocking on the door from inside the house without being seen from the outside. The traditional Tarma has a similar purpose to a "peephole" seen in many modern doors.

From observation, the Tamra has different shapes and forms such as half circle, square, triangle and rectangle (Figure 4). The differences in shape do not change its main purpose; however, the building's location within the settlement and the arrangement of the building's inner private spaces influenced the different forms of its shape. Similar to the doorway's visual representation mechanism, the desire for diversity by locals to personalize their buildings encouraged people to adopt different forms while creating a unified built environment. We typically observed the Tarma element in buildings that have a second floor. This is because the element's functional purpose is to help observe the street

(7) For more about how physical objects embody meanings (see Lawrence, 2013; Fenn, \& Hobbs, 2014; Gharib, \& Mohamed, 2015; Gelernter, 2015). and main door from above eye-level which causes buildings with only one floor to rarely have such an element ${ }^{8}$. In this way, the emergence of this element enhances the control and privacy levels in the built form by using the Tarma as the physical element for observing who is near the doorway and to control the privacy of the outside external streets from inside building spaces.

A possible relation to the differences seen in the element's shape to the principles is found in the hierarchal order of spaces, where the street type, width and location control the element's formation ${ }^{9}$. To elaborate on how street width controls the size of a Tarma, the study examined how much the element can extend from the wall. This is important because if a number of large Tarmas are on a narrow street they will conflict with each other and may reduce the daylight by obscuring the sky. To solve this issue, local people generated different shapes and sizes of the Tarma where house owners can benefit from the element in certain restricted areas. In this way, the element adapted through time and circumstance into different forms and sizes while preserving its main principle.

The benefit of the Tarma as an element is not limited to helping house occupants observe outside spaces from inside, it is also used as a symbolic element that signifies where the building door is located from a distance ${ }^{10}$. This element, where it exists, characterizes the exterior wall area near the doorway as the Tarma can be large and ornamented. This helps local people use it to navigate urban spaces and differentiate between neighbors' doors through recognition of the different formations of the element. From this

(8) We observed a couple examples of a Tarma element occurring in buildings with only one floor. In this situation, locals usually build a second floor only in the area above the door to accommodate the Tarma element. This partial second floor typically functions as a storage area and can be used later as a private room when the family expands, while the rest of the building remains one floor, thereby honoring the no harm principle.

(9) The process of generating the spatial and physical forms at the macro-level influenced and organized the connectivity and integration of different private urban masses (hellas), public open spaces, and public buildings. This process led specific architectural elements to relocate and function in certain areas to support daily life and needs (Alnaim, 2020).

(10) While a Tarma element helps a house occupant observe strangers near house doors, not all traditional buildings have them. From interviews in Ushaiqer (2017), old Riyadh (2018) and Alkhabra (2018) the element is used to recognize particular family house doors. This is because in some areas few houses have a Tarma, which makes distinguishing the doors that do have one easily recognizable from other doors that don't. 


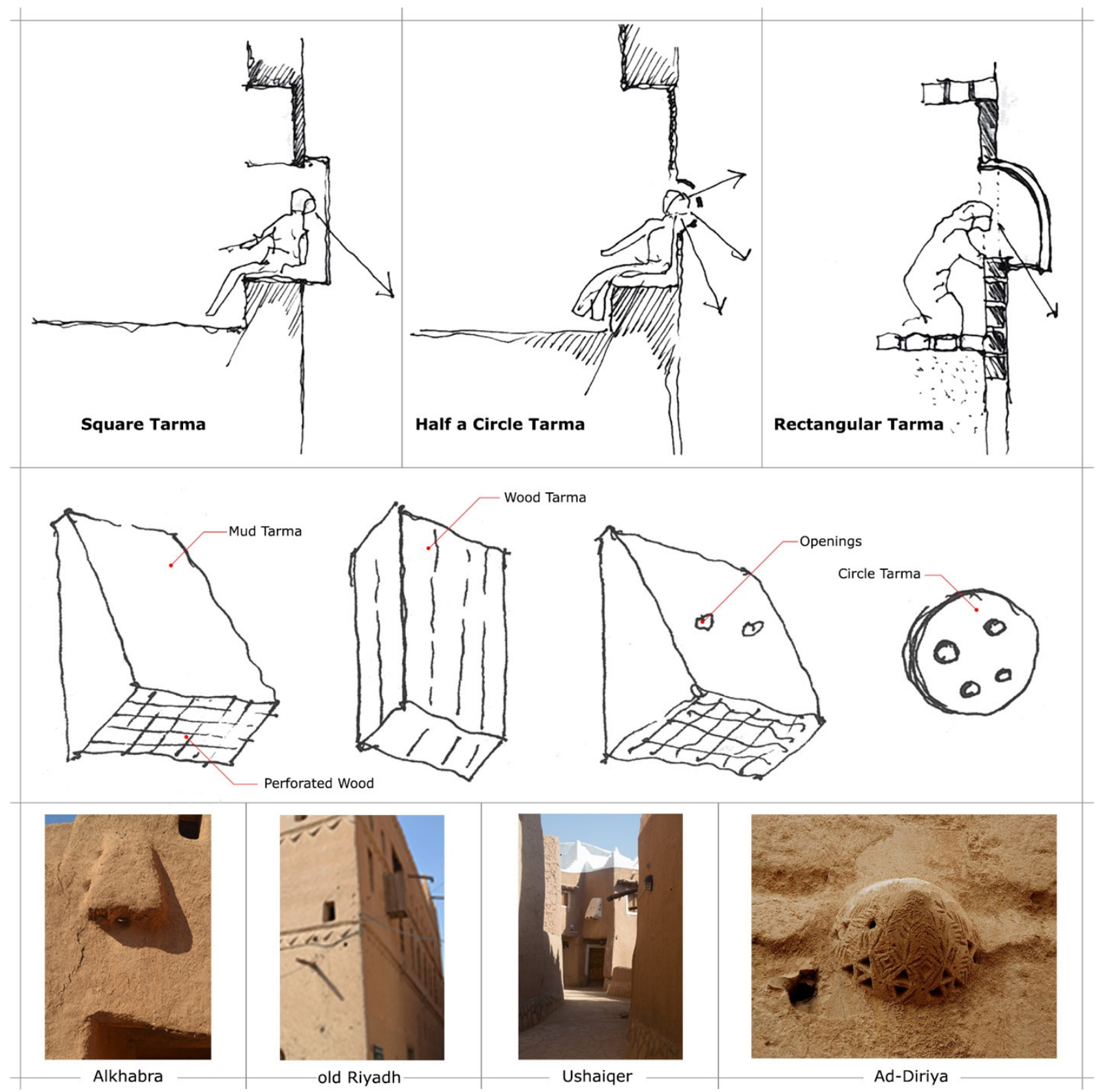

Figure 4. Tarma having different shapes and forms that function from inside to observe the outside streets in the traditional Najdi built environment. Source: Author

perspective, the Tarma is used as an element that increases the linkage between the urban spaces and building components in the traditional Najdi built environments by establishing a dual usage that benefits both urban spaces and indoor building spaces without disrupting its main principle.

\section{The Element of Alfuraj}

This element is a small window or aperture, locally called Alfuraj (pl. Furjat) that takes the shape of a triangle or rectangle. The naming comes from its meaning and function. Furjah means "an opening" in Arabic. We observed the element in settlement building walls to provide daylight 


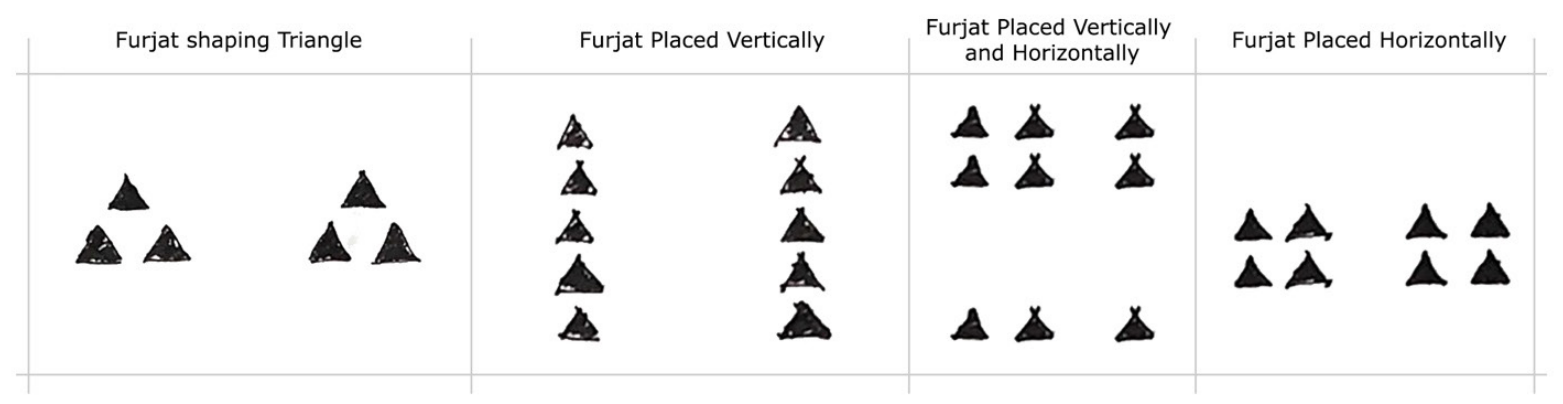

Figure 5. Basic patterns related to Alfuraj in the Najdi Built environment. Source: Author

and air, while in observation towers (attached to settlement walls) the element is used for defense. Furjat are usually located in the upper parts of a wall and close to the roof. The element's location is important, carefully located so that they do not expose the house's inner spaces visually to anyone outside, especially exposure from neighboring facing walls.

Mohammed Othman describes that in traditional rooms (e.g., guest space, kitchen, washrooms) there are two rows of Furjat that range between 20-35 cm in height (about 15 inches). The first row is located at the top of the wall, near the ceiling, and the second row is located below it, where the lower row contributes to the entry of cold air (Othman, 2000). The reason for the element to be small in size is to make it easy to close with mud or stone during winter seasons without effecting the building's structure (Alangari, 1996; Al-Anbar, 1999; Al-Nowssier, 1999; Al-Hathloul, 2016). While the Furjat contribute to the quality of light and air (ventilation) of the building, its aesthetic value is prominent as local people developed different ways for aligning and arranging the element in their walls (Figure 5).

The element of Alfuraj developed mainly to circulate the air flow and to provide daylight to inner spaces that do not have a direct link with the courtyard. The courtyard being located at the center of most traditional buildings means that deep rooms that have other inner spaces might not benefit from the courtyard's supply of light and air. Also, the high privacy expectations combined with the compactness of the traditional Najdi settlements regulated the openings to outside streets, where in some deep areas, the openings are highly restricted and required surrounding neighbors' agreement. From this perspective, local Najdi people developed Alfuraj to be an inside and outside element that meets their specific needs without affecting the privacy of other buildings.

By examining the element's location and physical appearance, the study identified two physical representations for how Furjat appear in the Najdi settlements. One physical representation orients itself toward the inside of the building, where the element is simple and more functional. The second physical representation is oriented toward the outside, where the element is more aesthetic and serves different functions (Figure 6). The building's location and size influenced both representations. If the building is located in deep areas, it is typically not feasible to implement the element outside (exterior walls). However, in deep areas, the study identified some cases where buildings implemented the element near the roof and with only a few Furjat with noticeable smaller openings than the others (in wide streets and open spaces) to manage privacy ${ }^{11}$.

In spaces with more depth, we observed that Alfuraj developed inside buildings because of limitations in the acceptable use of exterior walls. In these deeper areas a building usually has one façade and this wall faces a neighbor's façade which makes wall openings inconvenient due to privacy concerns and issues of visual conflict. Meanwhile, the need for daylight and fresh air in these areas led locals to develop Alfuraj inside their buildings to accommodate inner spaces that lack daylight and fresh air.

Inhabitants usually placed Alfuraj that are located on exterior walls above eye level and located the element in areas where the street is wider to

(11) Interviews with Ushaiqer local people on 1/7/2017 and Alkhabra local people on $1 / 1 / 2018$ to understand the varied patterns of the element. In addition, direct site observation was performed to examine the element's location in the traditional settlements. 


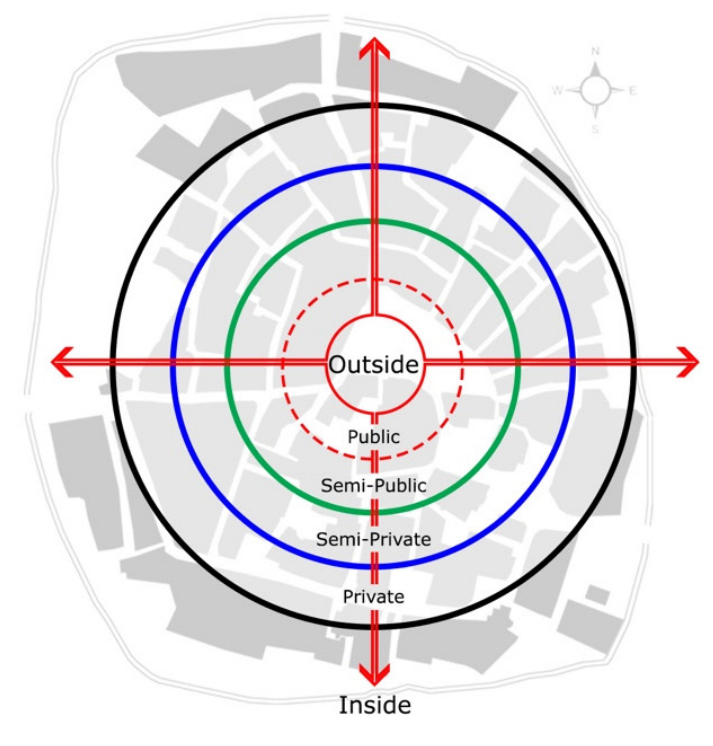

Example of Outside and Inside Appearance of Furjat Element

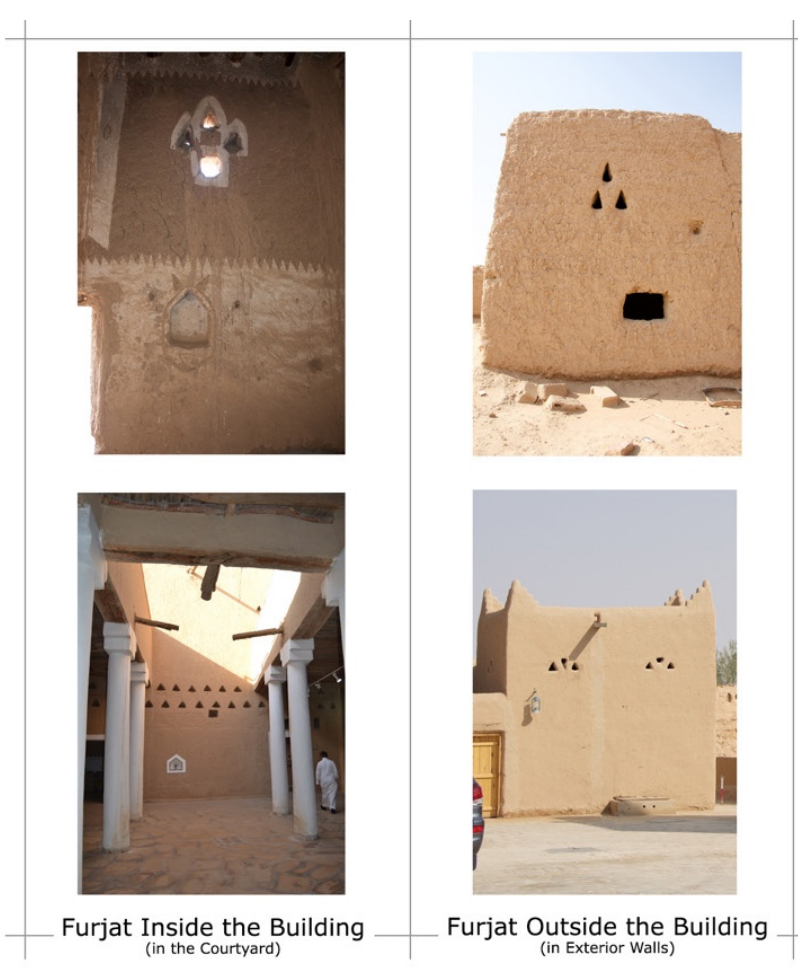

Figure 6. Two types of appearance related to the Alfuraj element based on building location. Source: Author

support such an action. The element here is observed in dense quantities in exterior walls only when buildings are located on wide streets and near open spaces $^{12}$. TheAlfurajelement, aside fromits functional use of providing light and ventilation, its variation in density and variation in formation, as we observed in different parts of the built form, functioned as an effective tool to reduce the severity of solid walls in compacted areas. Similar mechanism in the element of doorway, where doors face each other, usually appears only when the street is wide enough. This means that inhabitants used the same core concepts as the process that generated or regulated other elements that share similar principles in the built environment and modified them to fit the spatial order requirement in a specific place and space.

The importance of the Alfuraj element was in the element's ability to provide more options for air flow and daylight in traditional buildings.

(12) Based on a site observation done in old Riyadh, Alkhabra and Ushaiqer between 2017 and 2018. The element is usually located inside the buildings in dense private areas. However, it is noticed that some buildings have the element in their exterior walls when they are located in or near open areas or have two façade walls (e.g., the corner of a building).
Settlement inhabitants developed different ways to benefit from this element without restricting it to a specific social class or area. This is why the element maintained its functional role in both public and private areas, but with different placements and different physical representations, which contributed to personalizing the house's façade. In this sense, the Alfuraj, as an element was used to decorate the building's exterior walls by using different alignments, arrangements and density (Figure 6). The bigger the building, the more its walls can accommodate complex patterns of Furjat openings. Depending on how big the building wall is and its location within the settlement, the Alfuraj element expresses different patterns, which can indicate the social status and importance of the house's owner. This is important as the Najdi people living in the settlements tended to maximize benefit from any element, and use it in different ways to meet different socio-cultural needs while preserving the element's main environmental and technical purposes. 


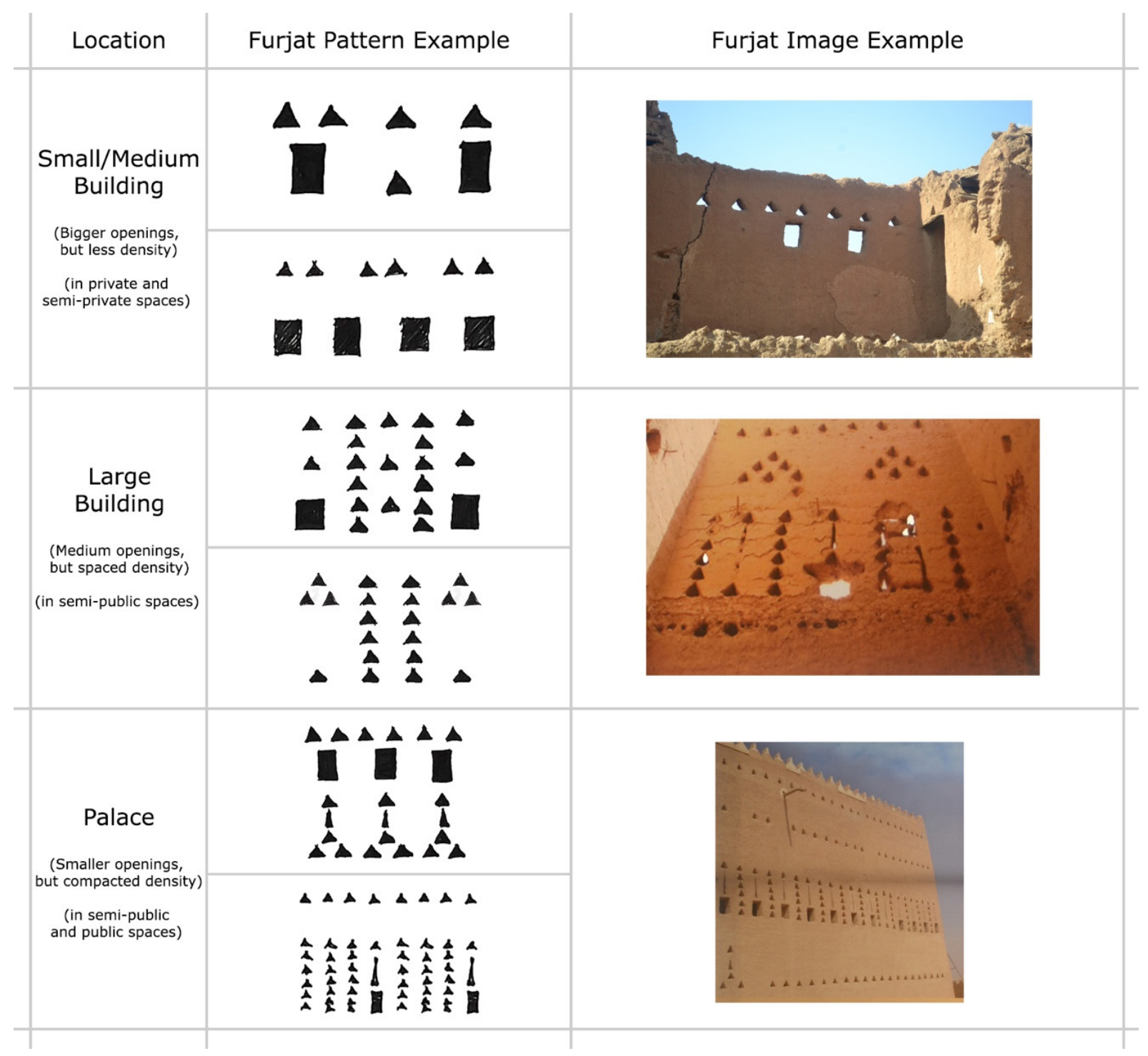

Figure 7. Complex patterns of Furjat elements in the façade. Source: Author

\section{The Element of Shuraf}

The name of the element of Shuraf (pl. Shurfat) comes from the Arabic word "Sharaf" or "Ashraf" which means "to observe" or "to look." It is located at the end of a building element or on its edge. The Shuraf element is both internal or external and inhabitants usually placed the element on a settlement's walls and on the façades of buildings (parapet). Shurfat are usually built with mud brick (adobe) and covered by local gypsum and painted white plaster, called "Nora," for decoration and to protect the mud parapet from rain. Physically, it has different representations such as curved lines, the shape of plant leaves, the shape of an arrow, straight lines, different angle positions, or a pyramid shape. (Abu-Ghazzeh, 1997; Al-Anbar, 1999; Aleid, 1999; Alnaim, \& Aba Al-Khail, 2010). In any form a Shuraf takes its shape, the head always points toward the sky. It is for that reason that the Najdi people as well as other Arab towns call it "A'arayis Alsama" (brides of heaven) (Jabalawi, 2012) ${ }^{13}$ (Figure 8).

A Shuraf, in general, extends a wall's height to provide privacy for the house's roof, which is especially important in the summer time, as in the

(13) Focus group interview with Ushaiqer local people on 1/7/2017 

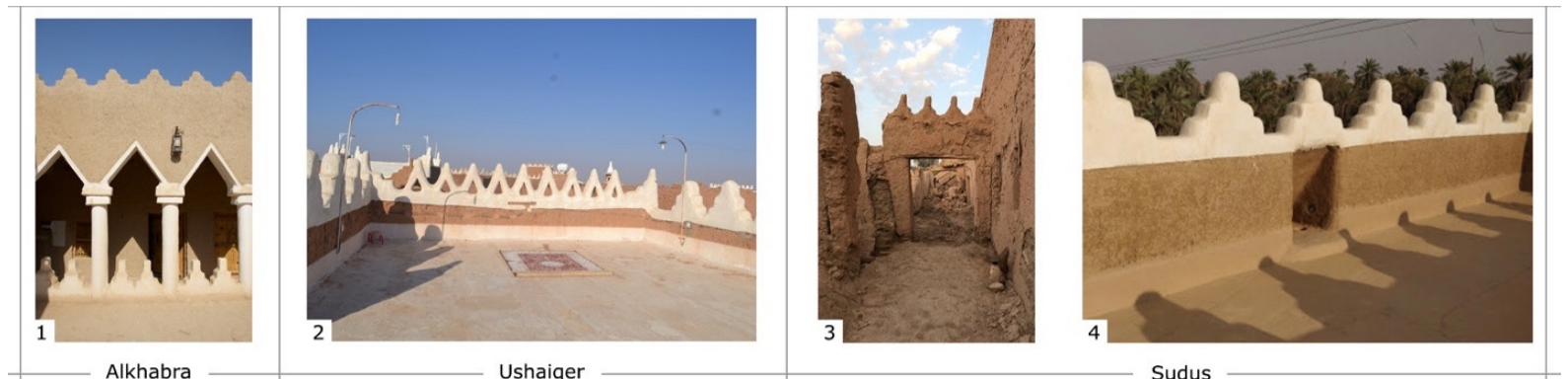

Figure 8. The Shurfat element in the traditional Najdi built environment. Source: $(1,2)$ Author, $(3,4)$ Inam AlHaq

summer the roof is used as a space for sleeping at night ${ }^{14}$. The increase in height here is not solid only, but graduates between solid and void which adds to the end of the building roof's aesthetic appearance. It defines the skyline of the buildings in the settlement. This, in fact, contributed to the element's abstraction by locals and its use inside the building with variant sizes as internal decorative elements, especially in the majlis (guest) space.

Similar to what is examined in previous elements, where some elements may contain the courtyard from visual exposure to neighbors, the Shurfat element is also employed as an extension of the wall inside the house to protect the courtyard from neighboring visual contact. It is one of the elements seen in partition roof walls where it can be a sign that both neighbors want their families to interact on the roof, while the common practice is to construct high solid walls on the roof between neighbors, providing privacy to both dwellings. This behavior of using the Shurfat element between adjacent houses usually occurs when relatives live next to each other. It also encouraged women to not use external streets to socialize with their neighbors as the integration of the roofs provided access among adjacent houses.

The other placement that a Shuraf takes is in the settlement's walls (fence) and fortified towers. While both locations (building and walls) visually have similar shapes, the implicit meaning that each placement embodies with the Shuraf is different. In buildings (within the settlement), a Shurf is meant to extend the building's walls and enable interaction with adjacent neighbors while giving the building (14) In a number of interviews conducted between 2017 and 2018, interviewees mentioned that the roof is used at night for sleeping to enjoy the cool air. Also see (Al-Nowaiser, 1999; Abu-Ghazzeh, 1996; Al-Hussayen; 1996; Alnaim, 2005; Othman, 2000; Al-Mohannadi, 2019). edges a pleasing aesthetic appearance, and in roofs as water protection while also defining the skyline of the settlement. In the settlement walls (fence), the element is meant to enhance security by enabling the people to observe any movement outside the settlement and to protect soldiers from exposure to the enemy when they engage in battle, where the solid shape is to protect the soldier, and the void space between two shurfat is intended to enable a soldier to engage the enemy.

By examining the placement of both functions of the Shurfat element, the study discovered that the density of the element varies. In settlement walls the element appears large, dense, and taller to express defense and protection (Figure 9 (4)), while in buildings within the settlement the density of the element in any building depends on the social status of its owner and the location of the building (Figure 9 (3)). The wealthier the household, the greater the number of Shurfat elements found on the roof parapet and around the courtyard (Alrewaq). This is why the element can be repeated along a building's walls or only at the edges of a building's corners (Figure 9 (1 \& 2)). However, both placements of Shurfat elements - both inside and outside the settlement - are similar, where the inside elements are physically more decorative and spaced out, while the outside elements are bulky and solid.

Like other elements discussed thus far, the location of the building is very important for how the Shurfat element was applied, where the building's location influenced the element's physical representation, exhibiting various patterns based on the building's location (Figure 10) ${ }^{15}$. Inhabitants understood and respected their

(15) A conclusion reached by conducting a number of focus group interviews from the five cases between 2016 and 2018 as well as conducting direct site observations to understand how the element varies across locations within the built form. 


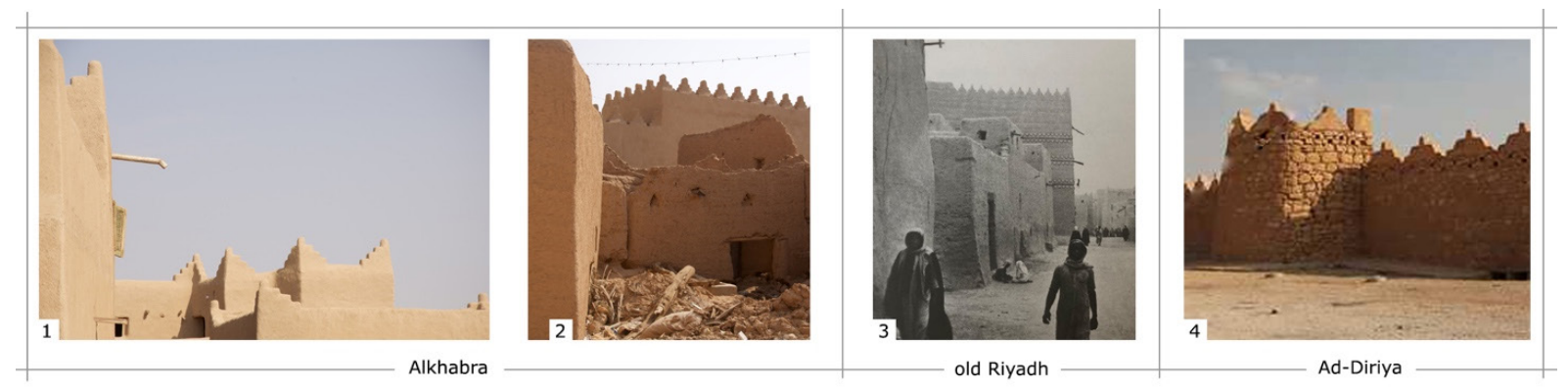

Figure 9. Different physical representations of the Shurfat element. Source: (1, 2) Author, (3) ADA, (4) Naif Al-Anzan
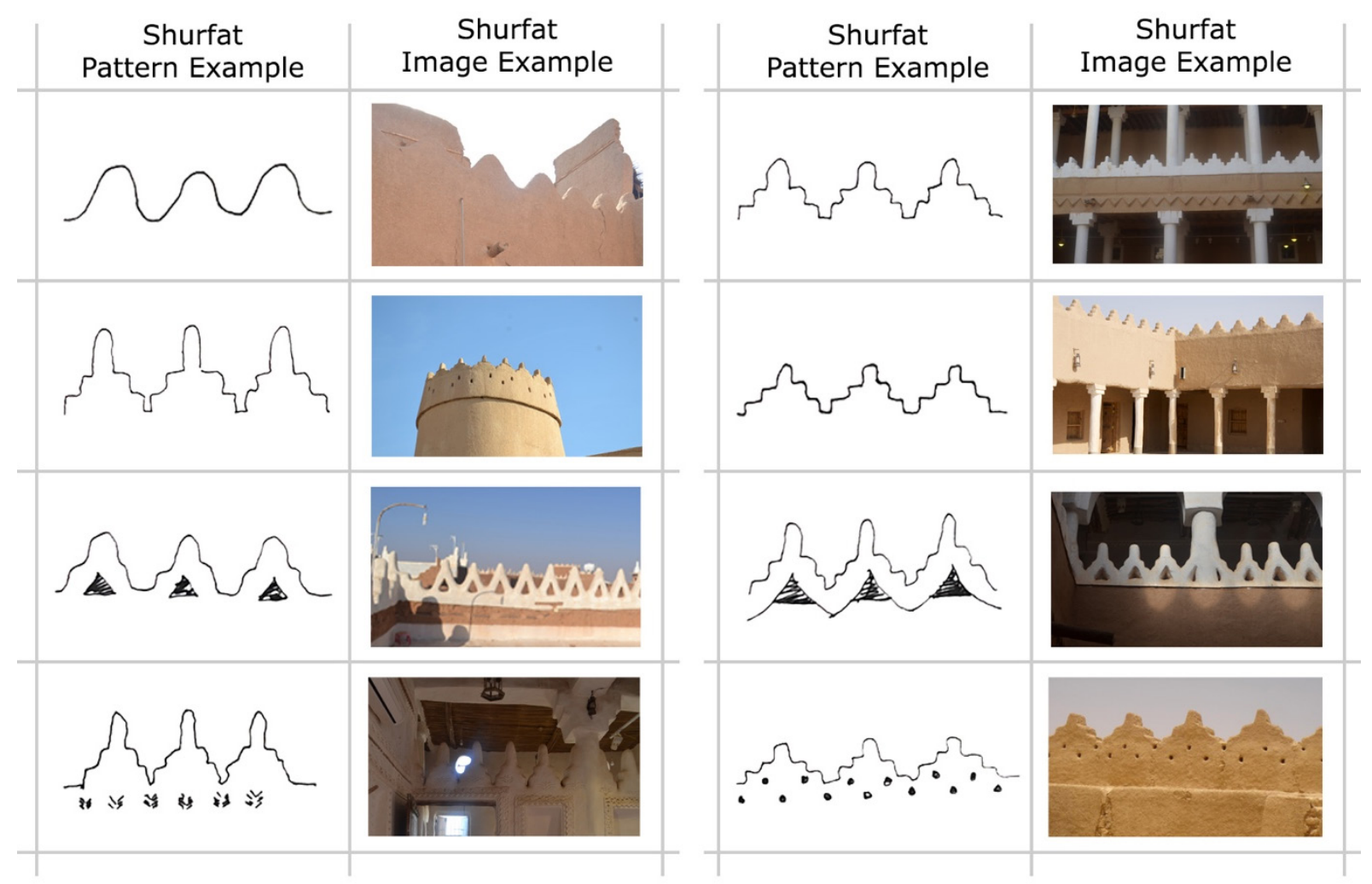

Figure 10. The different patterns of the Shurfat element. Source: Author

surroundings and any element seen in a specific place was a reflection of their understanding of the cultural setting. This makes the process of making places to not distinguish one domain from another (macro/micro levels); rather, the making process controls the level of interaction and integration of different architectural components, thereby preserving the characteristics of the Najdi architectural identity ${ }^{16}$. That is why locals developed the element of Shuraf to be dual usage element (inside and outside) that introduced an element

(16) This in fact is in response to the Islamic principle of "no harm." The principle governs how people assemble their urban and architectural components in such a way as to preserve their spaces while allowing the natural environment and building techniques to finalize their appearance. To respect the privacy of inhabitants, including the privacy of females in their houses that live close to a public building (see Akbar, 1981; Hakim, 1986; El-Shorbagy, 2010; Alnaim, 2013). 
used in houses to the inside to overcome the restricted requirements to the outside in dense and private areas, while giving buildings near open spaces and wide streets the flexibility to produce inside and outside elements. This type of generative process in the built environment preserved the homogeneity of the built form and maintained its characteristics over centuries.

\section{Conclusion and Recommendations}

The typological analysis of such traditional cases is undertaken in order to grasp the process of making the architectural elements and the parametric rules for generating different solutions concerning the identity of the place. Considering the four architectural Najdi elements examined, we described how the elements were implemented not merely to provide certain functional benefits. Settlement inhabitants also intended to benefit from the pleasing aesthetics of the elements as well as to encode social and cultural meanings into the architectural elements that are deeply held and shared by local inhabitants.

It is noted that the architectural elements in the building façades are sparse because of the introverted development of the traditional Najdi built environment. This sparse development led the architectural elements to be located either inside or between the buildings to serve and support multiple functions, which led to the repeated use of the elements, while shaping them in different ways according to their locations. The option to use repetitive elements to serve multiple functions gave the people located in different spaces and areas the ability to use the architectural elements differently to increase diversity, but within an overall unity to maintain their purpose.

The final appearance of the elements and their association with urban spaces and buildings depended on different mechanisms and the incremental decisions taken by the people during their interactions with the construction process in their built environment at the macro and microlevel. How the traditional settlement inhabitants produced their urban spaces and situated their buildings influenced the location and appearance of the architectural elements which, in turn, influenced the buildings' forms, façades, and internal elements. The flexibility in how and where to place and form the elements enabled the locals with the ability to interpret the elements based on their circumstances and conditions. The process of making generated by the inhabitants were profoundly guided by other principles; i.e., by spatial order, the demands of the natural environment, their construction ability, the materials available, as well as strongly felt socio-cultural values that were informed by deeply held religious beliefs and practices. We found that the pleasing aesthetics of the architectural elements becomes even more meaningful through developing an understanding of the various symbolic connotations of the elements. These connotations reach their climax when the physical object embodies socio-cultural meanings. Said more precisely: when an architectural element's appearance and its main function responded to resolving certain socio-cultural issues and aligned itself with strongly felt and highly valued religious convictions.

The analytical information presented in this paper can be transformed into design process tools that are useful for generating solutions for today's lifestyle and needs. Future studies may also examine other architectural elements of which Najdi architecture is rich, and incorporate the findings into more comprehensive tools that may be used to influence and characterize the contemporary built environment. This approach may serve to enhance the quality of local identity that is missing, without the need to simply 'copy and paste' from the past. Therefore, grasping the use and the embedded meanings of the architectural elements in the traditional built environment as a whole can be the first step in bridging the gap, providing a clear path forward in creating a contemporary visual expression that does communicate context of place as well as local inspiration.

\section{References}

Akbar, J. (1981). Responsibility and The Traditional Muslim Built Environment. Unpublished PhD thesis, Massachusetts Institute of Technology, USA

Aleid, S. (1994). The Role of Traditional Material Culture in Contemporary Saudi Arabia: The Traditional Courtyard House as Exemplar. Unpublished $\mathrm{PhD}$ thesis, The Ohio State University, USA

Alangari, A. (1996). The Revival of The Ar- 
chitectural Identity: The City of Arriyadh. Unpublished $\mathrm{PhD}$ Thesis, University of Edinburgh, United Kingdom

Al-Hussayen, A. (1996). Women and the Built Environment of Najd. Unpublished PhD Thesis, University of Edinburgh, United Kingdom

Abu-Ghazzeh, T. (1997) Vernacular Architecture Education in the Islamic Society of Saudi Arabia: Towards the Development of an Authentic Contemporary Built Environment, Habitat Int., Vol. 21, No. 2, pp. 229-253.

Al-Anbar, A. (1999). Interiors and their Decoration in The Traditional Mud-Brick Architecture of The Najd Region of Saudi Arabia and the Factors that have Influenced the Development of Interior Decoration and Spatial Organization. Unpublished PhD Thesis, Edinburgh College of Art, Edinburgh, UK

Al-Nowaiser, M. (1999). Characteristics of Urban Heritage in Saudi Arabia the Case of Najd Region. Al-Darah, Saudi Arabia (Arabic)

Alnaim, M. (2006). The Home Environment in Saudi Arabia and Gulf State: Growth of Identity crises and Origin of Identity. Crissma, Vol. 1, Milano

Alnaim, M., \& Aba Al-Khail, I. (2010). Riyadh City Architecture. Riyadh. Riyadh Municipality (Arabic)

Alnaim, M. (2015). Al-Fereej: Rituals and Ceremonies of the Traditional House in Alhasa, Saudi Arabia. Al-Turath, Saudi Arabia (Arabic)

Al-Hatloul, S. (2010). Arabic Islamic Cities: The Effect of Legislation in Shaping the Urban Environment. Umran, Riyadh, Saudi Arabia (Arabic)

Al-Hathloul, S. (2016). Awareness of urban heritage: Self-Explanatory, King Saud University (Arabic)

Arriyadh Development Authority (ADA). (2015) Riyadh: History, tradition and Vision. ADA, Riyadh, KSA (Arabic)

Al-Saud, K. (2017). Renovation of The Old Mud Village of Sadus, Saudi Arabia. WIT Transactions on The Built Environment, Vol. 171, pp. 323-333
Al-Mohannadi, A. (2019). Socio-Cultural Factors Shaping the Spatial Form of Traditional and Contemporary Housing in Qatar: A comparative analysis based on space syntax. Academia, Proceedings of the 12th Space Syntax Symposium, Vol. 285, pp. 1-19

Alnaim, M.M. (2020) The Hierarchical Order of Spaces in Arab Traditional Towns: The Case of Najd, Saudi Arabia. World Journal of Engineering and Technology, 8, 347-366

Benswessi, A.H. (1987) A Study of the Concept of Identity: Towards an Architecture as a Harmonious Identifiable Fabric. Unpublished Ph.D. Thesis, University of Pennsylvania, USA

Bloom, W. (1990) Personal Identity, National Identity and International Relations. Cambridge University Press, Cambridge, USA

Bianca, S. (2000). Urban Form in the Arab World Past and Present. Thames \& Hudson, Zurich

Duncan, J. (1981). From Container of Women to Status Symbol: The Impact of Social Structure on the Meaning of the House. In Housing and Identity: Cross-Cultural Perspective, Croom Helm, pp. 36-59

Damen, L. (1987). Culture Learning: The fifth Dimension on the Language Classroom. Reading, Ma: Addison Wesley.

El-Shorbagy, A. (2010). Traditional Islamic-Arab House: Vocabulary and Syntax. International Journal of Civil \& Environmental Engineering, IJENS, Vol. 10 No. 4,

Fenn, T., \& Hobbs, J. (2014). The Information Architecture of Meaning Making. Spring, pp. 11-20

Geertz, C. (1973). The Interpretation of Cultures. Selected Essays. Fontana Press, New York

Gharib, M., \& Mohamed, W.M.H. (2015). The Impact of Using Triangular Shapes on the Nubian and Najdi Architectural Composition. Vernacular Architecture: Towards a Sustainable Future, García Soriano \& Cristini (Eds), pp. 447-482

Gelernter, M. (2015). Making Room for Traditional Architecture. Traditional Building Magazine Online, pp. 1-12

Habraken, J. (1985). The Appearance of the Form. Awater Press, Cambridge 
Hakim, B. (1986). The "Urf" and its Role in Diversifying the Architecture of Traditional Islamic Cities. Journal of Architectural and Planning Research, pp. 108-126

Hakim, B. (1997). (Ed) Paul Oliver. Symbolism and Decoration. In Encyclopedia of Vernacular Architecture of the World, Cambridge University Press, Vol. 1, pp. 556-568

Hakim, B. (1990). The Islamic City and its Architecture: A Review Essay. Third World Planning Review, 12, pp. 75-89

Jomah, H. (2009). The Traditional Process of Producing A House in Arabia During The 18th And 19th Centuries: A CaseStudy of Hedjaz. Unpublished PhD Thesis, University of Edinburgh, England

Jabalawi, K. (2012). The meaning behind the Shuraf: brides of heaven. CAPS, Egypt

Lawrence, R. (2013). The Interpretation of Vernacular Architecture. Vernacular Architecture, 14(1), pp. 19-28

Mol, H. (1978). Identity and Religion: International, Cross-Cultural Approaches. SAGE Publication Ltd., London

Rapoport, A. (1969). House Form and Culture. Prentice Hall, N

Rapoport, A. (1977). Human Aspect of Urban Form: Towards a Man Environment. Pergamon Press, Oxford

Rapoport, A. (1987). On the Cultural Responsiveness of Architecture. Journal of Architecture Education, Vol. 41, No. 1, pp. 10-15

Rapoport, A. (2005). Culture, Architecture, and Design. Lock Science Publshing Company, Inc., Chicago

Ragette, F. (2012). Traditional Domestic Architecture of The Arab Region. American University of Sharjah Press, UAE

Othman, M. (2000). Sudus Traditional Architecture. Dar Alwafa, Egypt 


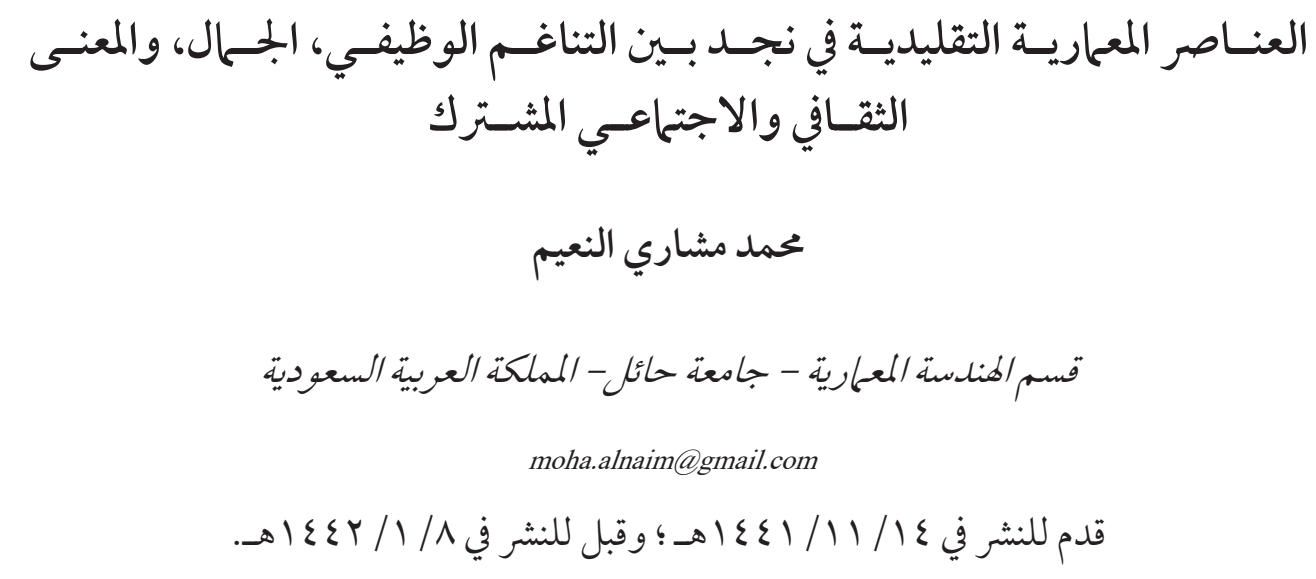

ملخص البحث. تُعد العناصر المِعمارية في المشهد الحضري مِن أهم المكونات التي ساهمت في صناعة الهوية

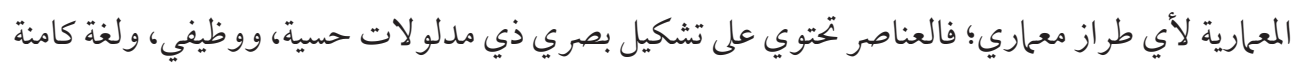

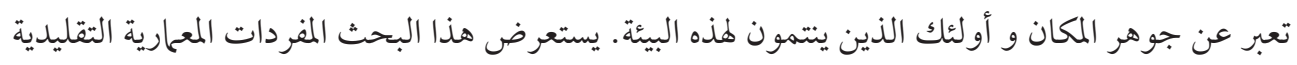

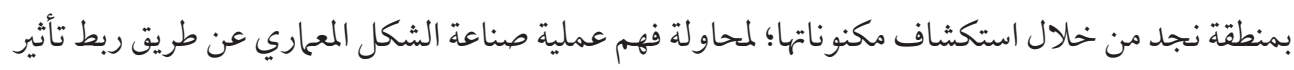
القيم الثقافية والاجتماعية والبيئية في هذه العملية. هذه الورقة تستعرض المفردات من منظور عملية صناعة

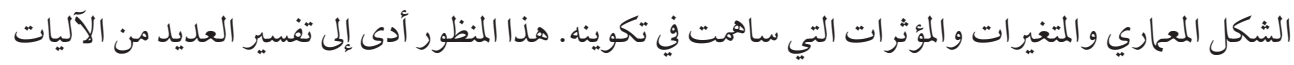
والمبادئ التي أثرت بشكل مباشر على العنصر المعماري وبشكل غير مباشر على البيئة التقليدية العمرانية في نجد. تخلص الدراسة إلى ضرورة فهم عملية صناعة الأشكال المعمارية وليس فقط التركيز على المنتج النهائي

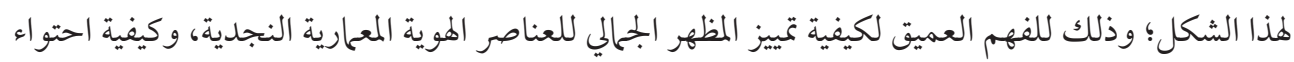

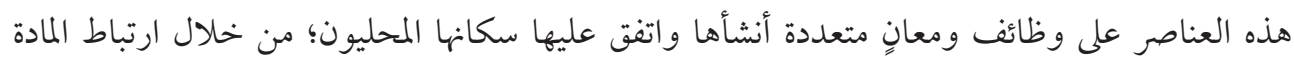
المحسوسة مع المعاني الكامنة لتكوين عناصر معمارية ذات معانٍ ورمزية.

الكلمات المفتاحية: عنصر؛ عنصر استدلالي؛ ثقافة؛ نجد؛ الشكل الحضري؛ نهج؛ مبادى؛ طَرَةَ؛ فُرجة؛ شُرفَة/ شُرَف. 